\title{
Systematic review and meta-analysis of endoscopic ultrasound drainage for the management of fluid collections after pancreas surgery
}

\author{
Ali Ramouz ${ }^{1}$. Saeed Shafiei ${ }^{1}$. Sadeq Ali-Hasan-Al-Saegh ${ }^{1}$ - Elias Khajeh ${ }^{1} \cdot$ Ricardo Rio-Tinto $^{2}$ - Sanam Fakour ${ }^{1}$. \\ Andreas Brandl $^{3}$. Gil Goncalves ${ }^{3}$. Christoph Berchtold ${ }^{1} \cdot$ Markus W. Büchler $^{1} \cdot$ Arianeb Mehrabi $^{1}$
}

Received: 9 December 2021 / Accepted: 13 February 2022 / Published online: 4 March 2022

(c) The Author(s) 2022

\begin{abstract}
Background The outcomes of endoscopic ultrasonography-guided drainage (EUSD) in treatment of pancreas fluid collection (PFC) after pancreas surgeries have not been evaluated systematically. The current systematic review and meta-analysis aim to evaluate the outcomes of EUSD in patients with PFC after pancreas surgery and compare it with percutaneous drainage (PCD).

Methods PubMed and Web of Science databases were searched for studies reporting outcomes EUSD in treatment of PFC after pancreas surgeries, from their inception until January 2022. Two meta-analyses were performed: (A) a systematic review and single-arm meta-analysis of EUSD (meta-analysis A) and (B) two-arm meta-analysis comparing the outcomes of EUSD and PCD (meta-analysis B). Pooled proportion of the outcomes in meta-analysis A as well as odds ratio (OR) and mean difference (MD) in meta-analysis B was calculated to determine the technical and clinical success rates, complications rate, hospital stay, and recurrence rate. ROBINS-I tool was used to assess the risk of bias.

Results The literature search retrieved 610 articles, 25 of which were eligible for inclusion. Included clinical studies comprised reports on 695 patients. Twenty-five studies (477 patients) were included in meta-analysis A and eight studies (356 patients) were included in meta-analysis B. In meta-analysis A, the technical and clinical success rates of EUSD were 94\% and $87 \%$, respectively, with post-procedural complications of $14 \%$ and recurrence rates of $9 \%$. Meta-analysis B showed comparable technical and clinical success rates as well as complications rates between EUSD and PCD. EUSD showed significantly shorter duration of hospital stay compared to that of patients treated with PCD.

Conclusion EUSD seems to be associated with high technical and clinical success rates, with low rates of procedure-related complications. Although EUSD leads to shorter hospital stay compared to PCD, the certainty of evidence was low in this regard.
\end{abstract}

Keywords Pancreatectomy $\cdot$ Collection $\cdot$ Ultrasonographic drainage $\cdot$ Drainage

Post-operative complications after pancreatic surgery can be life threatening and lead to major morbidity and mortality

Arianeb Mehrabi

arianeb.mehrabi@med.uni-heidelberg.de

1 Department of General, Visceral, and Transplantation Surgery, University Hospital Heidelberg, Im Neuenheimer Feld 420, 69120 Heidelberg, Germany

2 Department of Gastroenterology, Digestive Oncology Unit, Champalimaud Foundation, Lisbon, Portugal

3 Department of Digestive Surgery, Hepato-Pancreato-Biliary Surgery Unit, Champalimaud Foundation, Lisbon, Portugal
[1]. The most common complication after pancreatic surgery is peripancreatic fluid collection (PFC), which has been reported in up to $50 \%$ of cases [1-3]. PFC is caused by post-operative pancreatic leakage and occurs more often following central and distal pancreatectomy than following pancreaticoduodenectomy [2, 4-7]. Approximately 40\% of PFCs need to be treated to avoid further complications [1, $2,4]$. Following pancreaticoduodenectomy, enzymes within the pancreatic fluid are active and can harm the adjacent vessels and organs, resulting in bleeding, tissue necrosis, and abscess formation. The main indications for PFC drainage are pain, infection, an increase in diameter of PFC, and obstruction of the biliary tract and gastric outlet [8]. 
PFCs often extend toward visceral organs and form irregular shapes, which make it difficult to drain the fluid [9, 10]. For decades, PFCs have been predominantly managed through conservative approaches, such as jejunal feeding, parenteral nutrition, sclerotherapy, and antibiotics $[9,10]$. Surgical interventions have not been popular because of the increase in morbidity and mortality [4, 9-11]. Minimally invasive approaches, such as percutaneous drainage (PCD), showed better outcomes compared to surgical therapies and have promoted recovery [4, 9-11]. However, PCD has also been associated with a decreased quality of life due to the necessity of external drainage after discharge from hospital [12]. Furthermore, PCD increases the risk of persistent pancreas fistula $[1,13]$.

Recent studies have focused on endoscopic ultrasonography-guided drainage (EUSD) of PFC. EUSD has a high clinical efficacy and low morbidity and is considered the best option for managing pancreatic pseudocysts and PFCs [14-17]. Several advantages have been described for EUSD, such as the diagnostic possibility of fluid collection characterization. It also inflicts limited trauma on the surrounding tissue and shortens hospitalization [1, 13]. However, despite these advantages, the technical and clinical outcomes of EUSD have not been compared with those of other approaches, which prohibits the assessment of superiority. Larger sample sizes and longer follow-ups are needed to make reliable comparisons $[1,9,13]$.

The current systematic review and meta-analysis evaluated the outcomes of EUSD in treatment of patients with PFC after pancreatic surgery and compared them with PCD.

\section{Materials and methods}

This study was reported in accordance with the preferred reporting items for systematic reviews and meta-analyses (PRISMA) 2020 guidelines [18] and a PRISMA 2020 Checklist has been provided in Supplementary Tables 1 and 2 . We performed two meta-analyses-A and B. In metaanalysis A, a systematic review and a single-arm meta-analysis of studies reporting the outcomes of EUSD in patients with PFC was performed. In meta-analysis B, the outcomes of PCD and EUSD in patients with PFC were compared.

\section{Eligibility criteria}

The study question was formulated based on the population, intervention, comparison, outcome, and study design (PICOS) strategy. Studies were included in the study if they met the following criteria:

- Population Patients with post-pancreatectomy PFC
- Intervention EUSD to treat PFC after pancreatic resection

- Comparator None in meta-analysis A; PCD in metaanalysis B

- Outcome Technical success, time to drainage, clinical success, repeated drainage, hospital stay, and relevant perioperative data, including intra- and post-operative complications, as well as data regarding incidence of post-operative complications.

- Study design All study designs, except editorials and letter to editors.

To avoid analyzing the same patients more than once, the studies were thoroughly assessed and double publications and overlapping reports removed.

\section{Literature search}

A systematic literature search in Medline (via PubMed) and ISI Web of Science was conducted using the following search terms: "(Endoscopic Surgical Procedures[tiab] OR Endoscopic drainage[tiab] OR Percutaneous transgastric drainage[tiab] OR transgastric drainage[tiab] OR Percutaneous transgastric irrigation drainage[tiab] OR Gastrointestinal Endoscopy[tiab] OR Minimally Invasive Surgical Procedures[tiab] OR Transmural drainage[tiab]) AND (Collection[tiab] OR Pancreas Collection[tiab] OR Pancreatic Collection[tiab] OR Fistula[tiab] OR Pancreas fistula[tiab] OR Pancreatic fistula[tiab])." The search was not restricted to a specific study type or year of publication. The last query was performed in January 2022.

\section{Study selection and data extraction}

After screening titles and abstracts in selected electronic databases, the full texts of appropriate studies were evaluated, and their data were extracted by three investigators (SS, SAHS, and AR) independently. Discrepancies among these investigators were resolved through discussions with a senior author (AM). For each study, the following data were extracted: study characteristics, patient characteristics, study quality, and the abovementioned outcome measures.

\section{Definition of extracted data}

\section{Demographic and pre-treatment data}

Baseline data, including indication and type of primary pancreas surgery, PFC-related symptoms, and time to drainage, were obtained. 


\section{Post-treatment outcomes}

Technical success was defined as successful insertion of the stents into the PFC endoscopically, as well as access to and drainage of the contents. Repeated drainage was defined as an unsuccessful initial drainage that needed additional interventions. Clinical success was defined as the resolution of the PFC and its associated symptoms. Procedure-related complications were stent migration, perforation, bleeding, sepsis, infection, and PFC recurrence. The duration of hospital stay after interventions was also recorded.

\section{Quality assessment}

Two investigators (AR, SF) assessed bias in non-randomized studies using the ROBINS-I (Risk of Bias in Nonrandomized Studies of Interventions) tool [19]. The risk of bias was assessed by considering the seven bias domains of the ROBINS-I tool, as follows: (1) confounding; (2) selection of participants; (3) classification of interventions; (4) deviations from intended interventions; (5) missing data; (6) measurement of outcomes; and (7) selection of the reported result. The overall risk of bias was determined as low if the study was judged to be at low risk of bias for all domains. Moderate risk of bias was considered, if the study was judged to be at some concerns in at least one domain. The risk of bias was considered serious if the study was judged to be at serious risk of bias in at least one domain or if the study was judged to have some concerns in multiple domains in a way that substantially lowered confidence in the result. In case of missing concordance, two senior authors (AM, RRT) resolved the issue. To summarize and visualize the risk-of-bias assessments outcomes, the robvis tool was used [20].

The certainty of evidence was assessed by applying "The Grading of Recommendations Assessment, Development and Evaluation (GRADE)" approach [21], and a summary of findings table was designed for all outcomes using the GRADEpro GDT software (GRADEpro GDT: GRADEpro Guideline Development Tool [software]. McMaster University, 2020 (developed by Evidence Prime, Inc.). Available from https://gradepro.org).

\section{Statistical analysis}

For the single-arm meta-analysis, data proportions were analyzed using a random effects model. For the two-arm meta-analysis, dichotomous data were presented as odds ratios (OR) and continuous data as weighted mean differences (MD). Summary effect measures were presented along with their corresponding 95\% confidence intervals (CIs). Statistical heterogeneity was assessed using $\chi^{2}$ and inconsistency $\left(I^{2}\right)$ analyses, and the threshold for heterogeneity was a $P$ value lower than 0.05 or an $I^{2}$ value greater than $50 \%$. Publication bias was assessed using a funnel plot. The $\mathrm{R}$ software (version 4.0.1) and Meta package were used for data analysis.

\section{Results}

The literature search identified 264 articles, 25 of which met our eligibility criteria. These clinical studies reported 695 cases and were included in this meta-analysis [1, 10, 22-39] (Fig. 1). The articles were published between 2004 and 2021 and all had a retrospective non-randomized design. The baseline characteristics of the included studies are summarized in Table 1. Twenty-five studies (477 patients) were included in meta-analysis A and eight studies (356 patients) were included in meta-analysis B. Pre-procedural data of the patients and outcomes of the EUSD and PCD interventions are summarized in Tables 2 and 3, respectively.

A detailed summary of the risk of bias for non-randomized two-arm studies using ROBINS-I tool is listed in Supplementary Fig. 1. The level assessment for each outcome was varied between moderate and serious risk of bias. Overall risk of bias for technical success, clinical success, post-procedural complications, and PFC recurrence were assessed as serious due to missing data and selection of results domain. Overall risk of bias for hospital stay was reported at moderate. In Table 4, a detailed level of evidence is summarized in GRADE assessment tables for nonrandomized two-arm studies comparing EUSD and PCD in treatment of PFC after pancreas surgery, which provided low or very low level of certainty of evidence.

\section{Technical success}

In the single-arm meta-analysis of 24 studies, the technical success rate after EUSD was 94\% (431/438 cases; 95\% CI 91-97; $I^{2}=0 \%$; Heterogeneity-P=0.94) (Fig. 2A). The overall technical success rate reported in seven studies was 98.9\% for EUSD and $98.7 \%$ for PCD, and the two-arm metaanalysis revealed no significant between two techniques in means of technical success (OR 0.94, 95\% CI 0.14-6.12; $P=0.94 ; I^{2}=0 \%$; Heterogeneity-P $=0.45$; Fig. $3 \mathrm{~A}$ ).

\section{Clinical success}

The one-arm analysis of 24 studies indicated that the clinical success rate in the EUSD group was 87\% (421/473 cases; 95\% CI 82-91; $I^{2}=27 \%$; Heterogeneity-P $=0.11$ ) (Fig. 2B). In 16 studies, the authors reported the rate of re-intervention after EUSD due to unresolved symptoms or PFC. Of 246 patients, in 54 patients, the clinical circumstances after EUSD warranted repeated intervention, 


\section{Identification of studies via databases and registers}

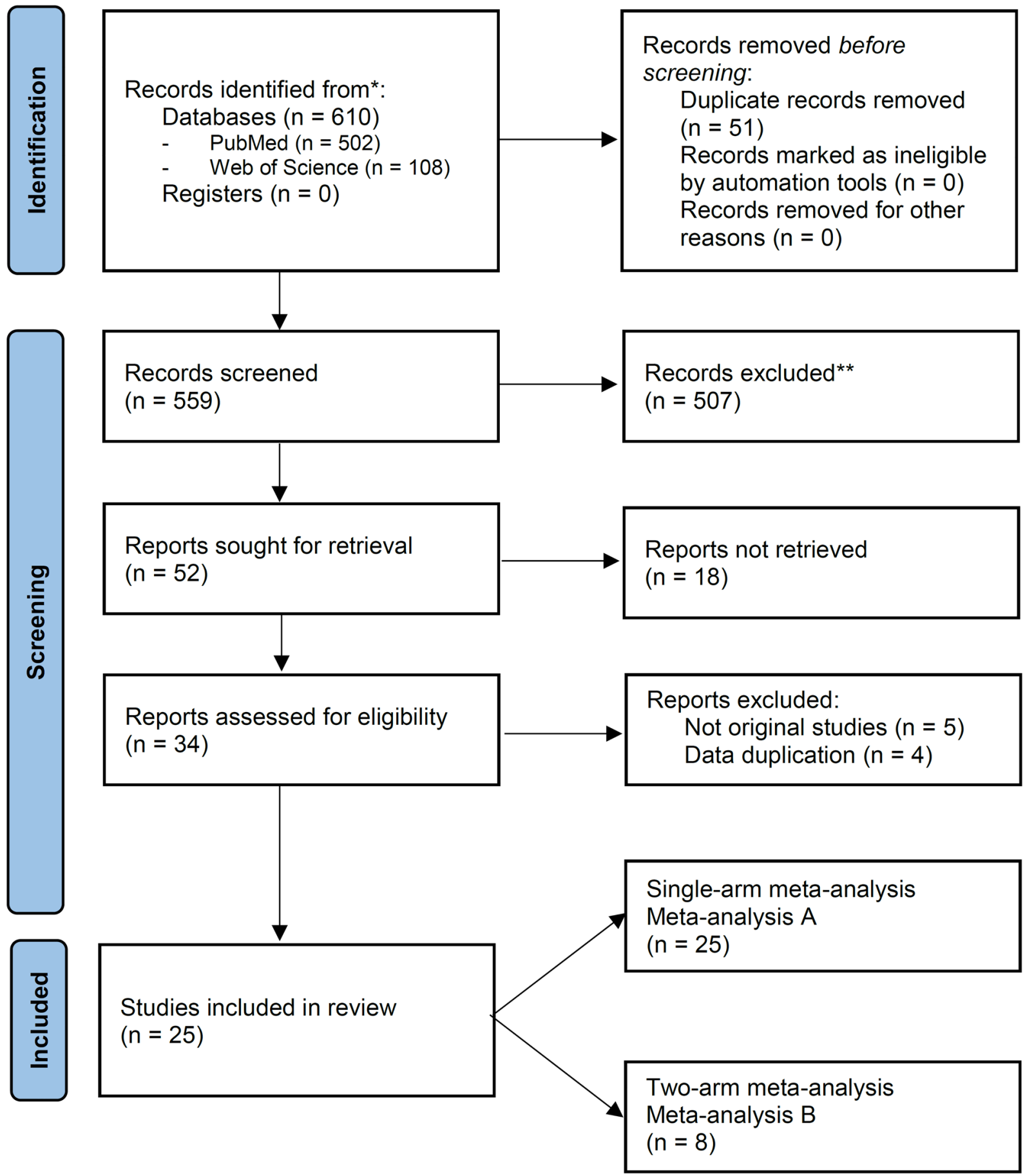

Fig. 1 PRISMA flow-chart showing selection of articles for review

which revealed a rate of $23 \%\left(95 \%\right.$ CI $17-31 ; I^{2}=20 \%$; Heterogeneity- $\mathrm{P}=0.23$ ).

In the comparative meta-analysis, eight studies reporting 356 cases gave the overall clinical success rate, which was $84.8 \%$ after EUSD and $76.6 \%$ after PCD. Albeit not significant, the meta-analysis showed higher rate of clinical success after EUSD compared to PCD (OR 1.9, 95\% CI $0.95-3.81 ; P=0.06 ; I^{2}=12 \%$; Heterogeneity-P $=0.34$ ) (Fig. 3B). 
Table 1 Baseline characteristics and pre-procedural data of the patients that underwent EUSD

\begin{tabular}{|c|c|c|c|c|c|c|c|c|c|c|c|}
\hline \multirow[t]{2}{*}{ Author, year } & \multirow[t]{2}{*}{ Country } & \multirow[t]{2}{*}{ Study design } & \multicolumn{2}{|c|}{ Sample size } & \multirow[t]{2}{*}{ Gender (M/F) } & \multicolumn{4}{|c|}{ Type of pancreas surgery } & \multicolumn{2}{|c|}{$\begin{array}{l}\text { Meta- } \\
\text { analysis }\end{array}$} \\
\hline & & & EUSD & PCD & & $\begin{array}{l}\text { Distal } \\
\text { pancreatec- } \\
\text { tomy }\end{array}$ & $\begin{array}{l}\text { Pancreati- } \\
\text { coduodenec- } \\
\text { tomy }\end{array}$ & $\begin{array}{l}\text { Central } \\
\text { pancreatec- } \\
\text { tomy }\end{array}$ & Other & A & B \\
\hline Wang, 2021 [54] & China & Retrospective & 15 & - & $5 / 10$ & 8 & 7 & - & - & $\mathrm{x}$ & - \\
\hline Miranda, 2021 [36] & Germany & Case report & 1 & - & $0 / 1$ & 1 & - & - & - & $\mathrm{x}$ & - \\
\hline Storm, 2020 [26] & USA & Retrospective & 75 & - & - & 63 & 3 & - & 9 & $\mathrm{x}$ & - \\
\hline Al Efishat, 2019 [24] & USA & Retrospective & 39 & 39 & $39 / 39$ & 48 & 20 & 6 & 4 & $\mathrm{x}$ & $\mathrm{x}$ \\
\hline Tamura, 2019 [25] & Japan & Retrospective & 13 & 28 & $26 / 15$ & 23 & 18 & - & - & $\mathrm{x}$ & $\mathrm{x}$ \\
\hline Caillol, 2019 [1] & France & Retrospective & $35(41)^{\dagger}$ & - & - & 26 & 7 & 2 & - & $\mathrm{x}$ & - \\
\hline Donatelli, 2018 [23] & France & Retrospective & 10 & - & - & - & & & & $\mathrm{x}$ & - \\
\hline Ilie, 2018 [32] & Romania & Retrospective & 2 & - & $2 / 0$ & - & & & & $\mathrm{x}$ & - \\
\hline Jürgensen, 2018 [55] & Germany & Retrospective & 39 & 59 & $50 / 48$ & - & & & & $\mathrm{x}$ & $\mathrm{x}$ \\
\hline Futagawa, 2017 [22] & Japan & Retrospective & 12 & 21 & $22 / 11$ & 18 & 13 & 2 & - & $\mathrm{x}$ & $\mathrm{x}$ \\
\hline Mudireddy, 2017 [31] & USA & Retrospective & 26 & - & - & 23 & 3 & - & - & $\mathrm{x}$ & - \\
\hline Chen, 2016 [56] & USA & Retrospective & 40 & - & $22 / 18$ & - & 40 & - & - & $\mathrm{x}$ & - \\
\hline Denzer, 2016 [9] & Germany & Retrospective & 20 & - & $8 / 12$ & 14 & 3 & - & 3 & $\mathrm{x}$ & - \\
\hline Tilara, 2014 [10] & USA & Retrospective & 31 & - & $13 / 18$ & 15 & 9 & 7 & - & $\mathrm{x}$ & - \\
\hline Kurihara, 2013 [35] & Japan & Retrospective & 14 & - & $7 / 7$ & - & 14 & - & - & $\mathrm{x}$ & - \\
\hline Kwon, 2013 [30] & USA & Retrospective & 12 & 14 & $9 / 14$ & 21 & - & - & 2 & $\mathrm{x}$ & $\mathrm{x}$ \\
\hline Azeem, 2012 [28] & USA & Retrospective & 15 & 33 & $15 / 33$ & 48 & - & - & & $\mathrm{x}$ & $\mathrm{x}$ \\
\hline Onodera, 2012 [39] & Japan & Retrospective & 6 & 18 & $17 / 7$ & 6 & 18 & - & - & $\mathrm{x}$ & $\mathrm{x}$ \\
\hline Gupta, 2012 [27] & Belgium & Retrospective & 23 & - & - & - & & & & $\mathrm{x}$ & - \\
\hline Varadarajulu, 2011 [47] & USA & Retrospective & 20 & - & $6 / 14$ & 20 & - & - & - & $\mathrm{x}$ & - \\
\hline Ergun, 2011 [33] & Belgium & Retrospective & 10 & - & $6 / 4$ & - & 10 & & - & $\mathrm{x}$ & - \\
\hline Grobmyer, 2009 [37] & USA & Retrospective & 2 & 6 & $5 / 3$ & 8 & - & - & - & $\mathrm{x}$ & $\mathrm{x}$ \\
\hline Varadarajulu, 2009 [29] & USA & Retrospective & 10 & - & $6 / 4$ & 10 & - & - & - & $\mathrm{x}$ & - \\
\hline Kahaleh, 2007 [34] & USA & Retrospective & 5 & - & - & - & 5 & - & - & $\mathrm{x}$ & - \\
\hline Seewald, 2004 [38] & Germany & Retrospective & 2 & - & $1 / 1$ & 2 & - & - & - & $\mathrm{x}$ & - \\
\hline
\end{tabular}

$E U S D$ endoscopic ultrasonography-guided drainage, $P C D$ percutaneous drainage

${ }^{\dagger}$ Six patients with pancreatic enucleation were removed from further analysis, and totally 35 patients were included from this study

\section{Post-procedural complications}

Twenty studies describing 403 cases reported complications after EUSD. The one-arm analysis revealed a post-procedural complication rate of $14 \%\left(95 \%\right.$ CI $9-20 ; I^{2}=37 \%$; Heterogeneity-P $=0.05$ ) (Fig. $2 \mathrm{C}$ ). Eight studies describing 356 cases compared the outcomes of EUSD (138 cases) and PCD (218 cases). The meta-analysis revealed a lower rate of post-procedural complications after EUSD, but this was not statistically significantly compared to rate of post-procedural complications after PCD (OR 0.69; 95\% CI 0.24-1.98; $P=0.49 ; I^{2}=18 \%$; Heterogeneity-P $=0.30$ ) (Fig. $3 \mathrm{C}$ ).

\section{Hospital stay}

In means of two-arm meta-analysis, the duration of hospital stay was reported in 40 patients with PFC after EUSD and in 77 patients with PFC after PCD. The meta-analysis showed that the length of hospital stay was significantly shorter after EUSD than after PCD (mean difference: - 3.84; $95 \% \mathrm{CI}-6.12$ to $-1.55 ; P<0.01, I^{2}=14 \%$; Heterogeneity$\mathrm{P}=0.31)($ Fig. 3D).

\section{PFC recurrence}

PFC recurrence after EUSD was reported in 21/363 patients from 20 studies. One-arm analysis showed that the incidence of PFC recurrence after EUSD was 9\% (95\% CI 6-14; $I^{2}=8 \%$; Heterogeneity-P $=0.35$ ) (Fig. 2D). In six studies reporting 193 cases, PFC recurrence was $6.9 \%$ after EUSD and $7.2 \%$ after PCD and these rates were not significantly different according to the two-arm meta-analysis (OR 1.12; 95\% CI $0.27-4.76 ; P=0.87 ; I^{2}=28 \%$; Heterogeneity$\mathrm{P}=0.25)$ (Fig. 3E). 


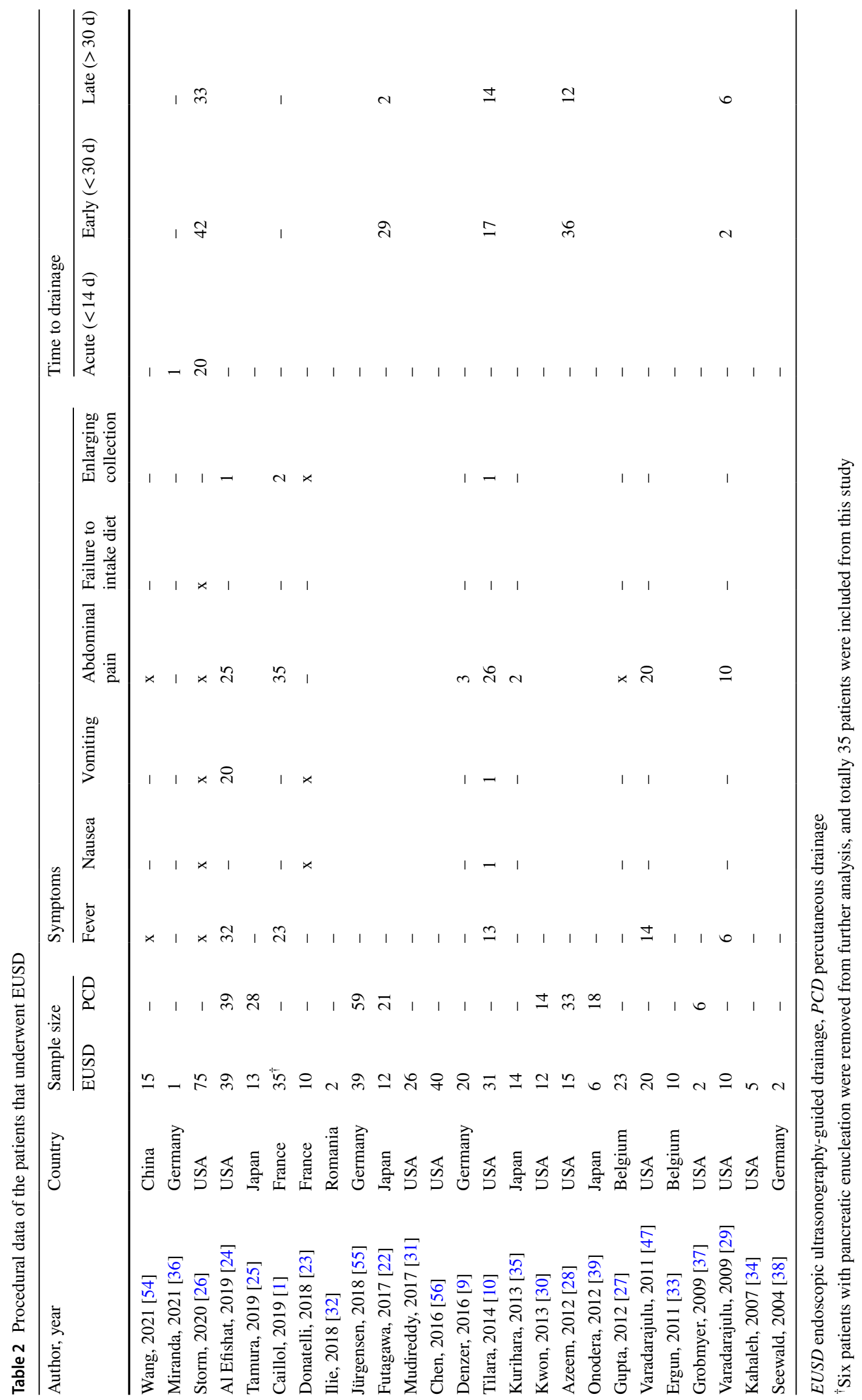




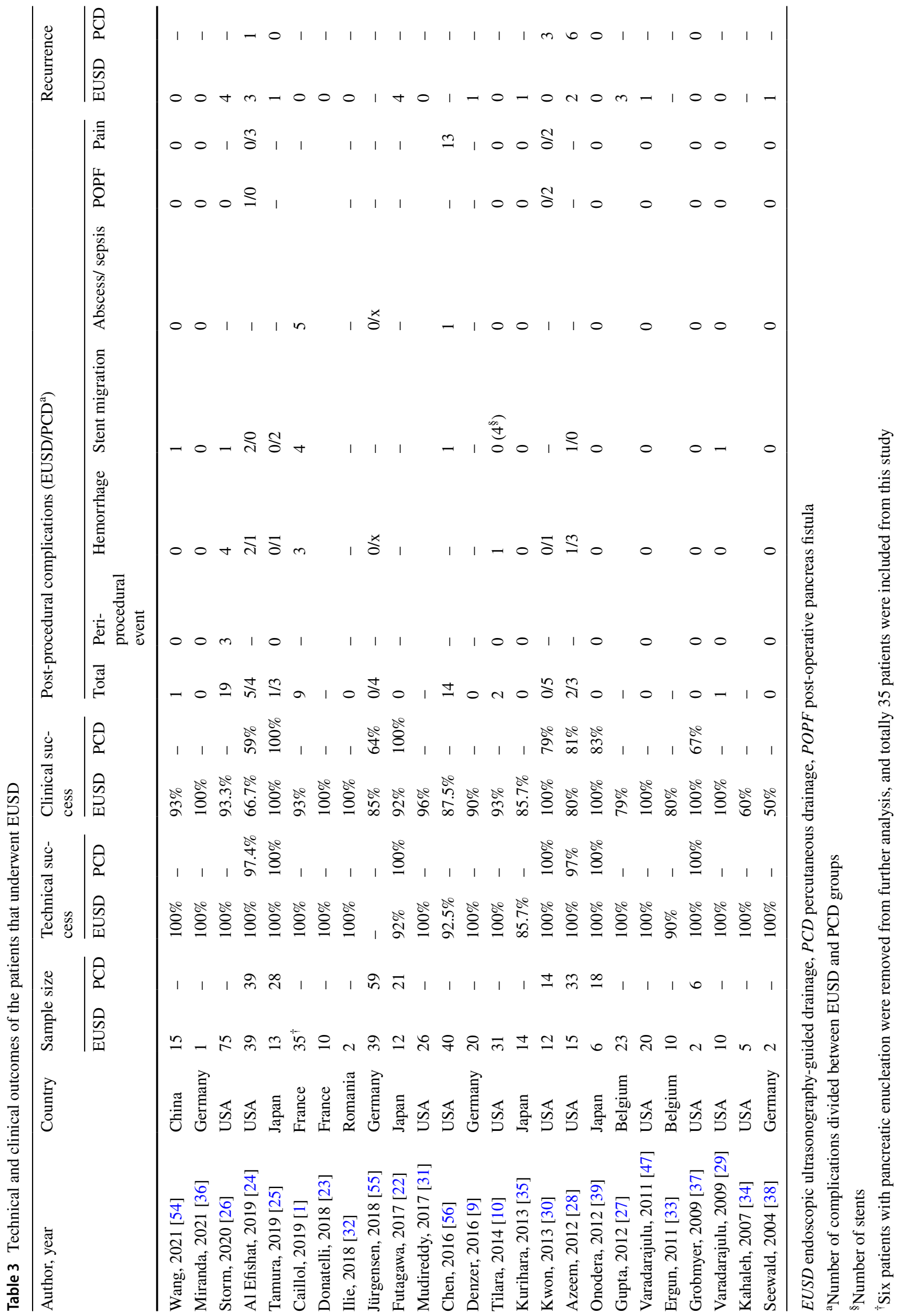




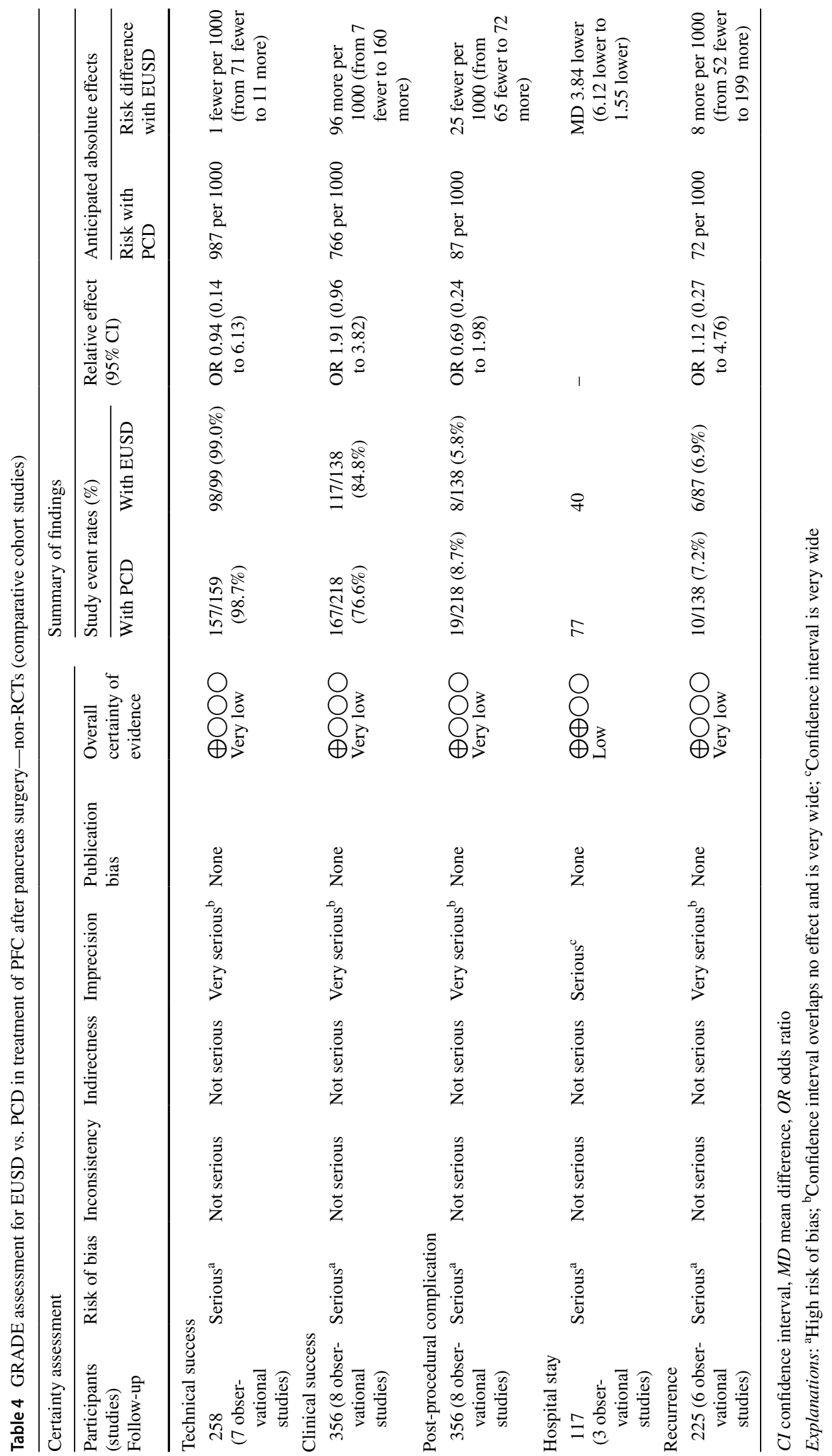






Fig. 2 Forest plot of the single-arm meta-analysis (meta-analysis A) of EUSD outcomes; A technical success, $\mathbf{B}$ clinical success, $\mathbf{C}$ post-procedural complications rate, and $\mathbf{D}$ recurrence rate

\section{Discussion}

In this study, we compared the outcomes of EUSD and PCD in patients with PFC after pancreatic surgery. Our single-arm meta-analysis showed that EUSD achieved a technical success rate of $94 \%$ and a clinical success rate of $87 \%$. The complication rate was $14 \%$ with a PFC recurrence rate of $9 \%$ after EUSD. Our two-arm meta-analysis showed no significant difference neither in technical nor in clinical success rates between EUSD and PCD. However, patients had a significantly shorter hospital stay after EUSD compared to PCD. The rate of PFC recurrence was also similar between these two techniques. None of the included studies reported procedure-related mortality.

In a previous systematic review and meta-analysis, Mahon et al. reported a technical success rate of $97 \%$ and a clinical success rate of $93 \%$ after EUSD, which was comparable to the provided single-arm meta-analysis [13]. However, unlike our study, Mohan et al. observed a significantly higher clinical success rate after EUSD than after PCD. This discrepancy may be explained by the use of pooled data analysis to compare outcomes between groups in the Mohan et al. study as well as the inclusion of patients after all pancreatic procedures in their study [13]. We performed a two-arm meta-analysis with nonsignificant heterogeneity, which is a more reliable method of comparing EUSD with PCD. The rate of procedurerelated complications after EUSD was $9.3 \%$ in the study by Mohan et al., which was similar to our findings. PFC recurrence after EUSD was 9.4\% in the Mohan et al. study, which was comparable to our rate of $9 \%$. This discrepancy may be explained by differences of the included studies and approaches to data analysis.

PFC that are suitable for endoscopic drainage are endoscopically accessible and located within $1 \mathrm{~cm}$ of the duodenal or gastric walls [40, 41]. Indications for EUSD include unusual location of the collection, small window of entry, non-bulging collections, coagulopathy, intervening varices, failed conventional transmural drainage, indeterminate adherence of PFC to the luminal wall, or suspected malignancy. EUSD is also a feasible option for draining PFCs with a septum, when PCD might be difficult. It has been suggested that PFC should be drained by EUSD at least four weeks after the surgery to allow a thick capsule to form around the collection [22]. Nonetheless, other studies have shown acceptable outcomes when EUSD was performed less than 2 weeks after surgery. In the current study, most patients $(69 \%)$ received EUSD less than 4 weeks after surgery, which was confirmed by recent studies showing a trend to earlier application of EUSD after PFC diagnosis than previously reported. These findings suggest that PFCs can be drained by EUSD during 
Fig. 3 Forest plot of the two-arm comparison (metaanalysis B) of EUSD and PCD outcomes; A technical success, B clinical success, $\mathbf{C}$ postprocedural complication rate, $\mathbf{D}$ duration of hospital stay, and $\mathbf{E}$ PCF recurrence rate

\begin{tabular}{|c|c|c|c|c|}
\hline $\begin{array}{l}\text { A } \\
\text { Study }\end{array}$ & Events & $\begin{array}{l}\text { USD } \\
\text { otal }\end{array}$ & Events & PCl \\
\hline Al-Esfihat 2019 & 39 & 39 & 38 & \\
\hline Tamura 2019 & 13 & 13 & 28 & \\
\hline Futagawa 2017 & 11 & 12 & 21 & \\
\hline Kwon 2013 & 12 & 12 & 14 & \\
\hline Azeem 2012 & 15 & 15 & 32 & \\
\hline Onodera 2012 & 6 & 6 & 18 & \\
\hline Grobmyer 2004 & 2 & 2 & 6 & \\
\hline $\begin{array}{l}\text { Random effects model } \\
\text { Heterogeneity: } I^{2}=0 \%, \tau^{2}\end{array}$ & $\begin{array}{r}98 \\
=0, p=0\end{array}$ & 99 & 157 & \\
\hline
\end{tabular}

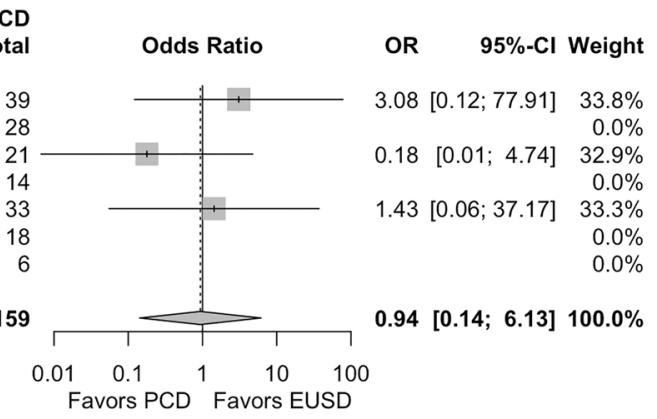

B

Study

EUSD PCD

Al-Esfihat 2019

Tamura 2019

Jürgensen 2018

Futagawa 2017

Kwon 2013

Azeem 2012

Onodera 2012

Grobmyer 2004

$36-39$

$\begin{array}{rr} & \text { Total } \\ 23 & 39 \\ 28 & 28 \\ 38 & 59 \\ 21 & 21 \\ 11 & 14 \\ 27 & 33 \\ 15 & 18 \\ 4 & 6\end{array}$

Random effects model $\quad 117 \quad 138$

$167 \quad 218$

Heterogeneity: $I^{2}=12 \%, \tau^{2}=0.1052, p=0.34$

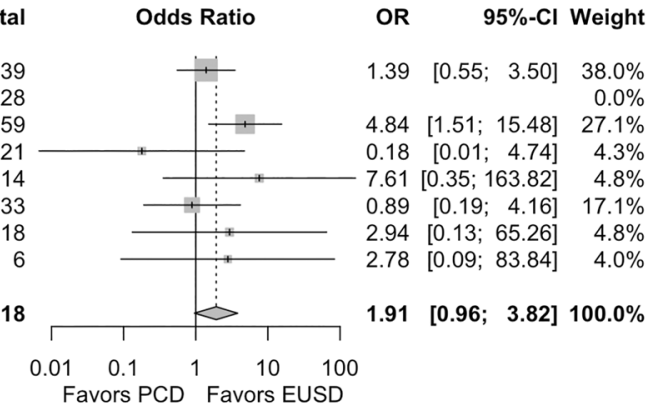

C EUSD PCD Study Events Total Events Total

Odds Ratio

$$
\begin{aligned}
& \text { Al-Esfihat } 2019 \\
& \text { Tamura } 2019 \\
& \text { Jürgensen } 2018 \\
& \text { Futagawa } 2017 \\
& \text { Kwon } 2013 \\
& \text { Azeem } 2012 \\
& \text { Onodera } 2012 \\
& \text { Grobmyer } 2004
\end{aligned}
$$

Random effects model

Heterogeneity: $I^{2}=18 \%, \tau^{2}=0.2720, p=0.30$

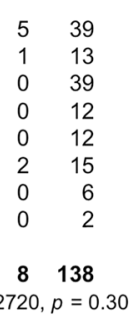

$\begin{array}{rr}4 & 39 \\ 3 & 28 \\ 4 & 59 \\ 0 & 21 \\ 5 & 14 \\ 3 & 33 \\ 0 & 18 \\ 0 & 6\end{array}$

$19 \quad 218$

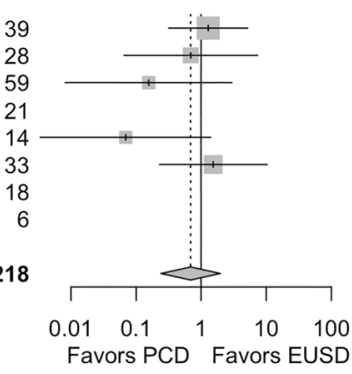

D

Study

Al-Esfihat 2019

Futagawa 2017

Azeem 2013

Random effects model $\quad 40$

Heterogeneity: $I^{2}=14 \%, \tau^{2}=0.9268, p=0.31$

EUSD PCD

1212.508 .67

1321.009 .84

$\begin{array}{lr}15 & 4.50 \\ 2.30\end{array}$

$\begin{array}{lll}21 & 13.00 & 8.68 \\ 28 & 22.75 & 8.37\end{array}$

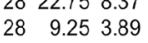

77

D

Mean Difference

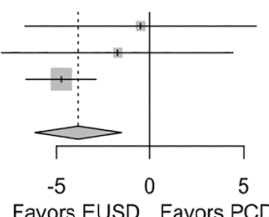

Favors EUSD Favors PCD

OR $\quad 95 \%-\mathrm{Cl}$ Weight

$1.29[0.32 ; 5.20] \quad 37.1 \%$ $0.69[0.07 ; 7.40] \quad 16.7 \%$ $0.16[0.01 ; 2.98] 11.4 \%$ $0.07 \quad[0.00 ; 1.41] \quad \begin{array}{r}0.0 \% \\ 11.0 \%\end{array}$ $1.54[0.23 ; 10.33] \quad 23.8 \%$ $23.8 \%$
$0.0 \%$
$0.0 \%$

$0.69[0.24 ; 1.98] 100.0 \%$

MD $\quad 95 \%-\mathrm{Cl}$ Weight

$-0.50[-6.65 ; 5.65] \quad 12.6 \%$ $-1.75[-7.93 ; 4.43] \quad 12.5 \%$ $-4.75[-6.60 ;-2.90] \quad 74.8 \%$

$-3.84[-6.12 ;-1.55] 100.0 \%$

E) Study EUSD
Events Total Events Total

Odds Ratio OR 95\%-Cl Weight

Al-Esfihat 2019

Tamura 2019

Kwon 2013

Azeem 2012

Onodera 2012

Grobmyer 2004

$\begin{array}{rr}3 & 39 \\ 1 & 13 \\ 0 & 12 \\ 2 & 15 \\ 0 & 6 \\ 0 & 2\end{array}$

Random effects model

$6 \quad 87$

Heterogeneity: $I^{2}=28 \%, \tau^{2}=0.6057, p=0.25$

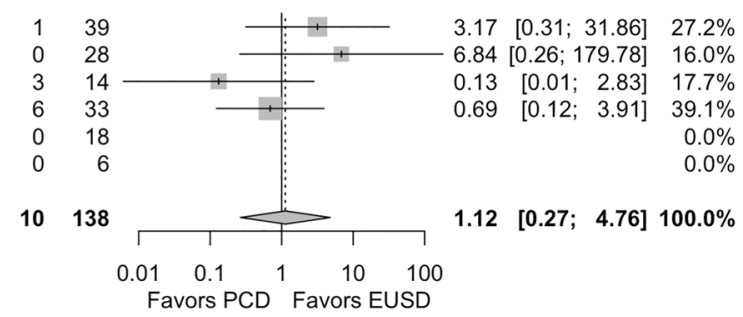


the early post-operative period with excellent outcomes. EUSD has also proven to be feasible during the early post-operative period in patients with PFC after pancreaticoduodenectomy [39]. Despite the technical difficulty and anatomic variations, EUSD provides the opportunity to visualize anatomically important structures.

In addition to its technical feasibility and safety, EUSD has also been shown to improve quality of life and reduce the risk of infection [42]. Even in patients with infectious PFC, draining the fluid into the stomach via EUSD did not result in fever, gastroenteritis, or retrograde infection [22, 27]. Furthermore, EUSD prevents fluid and electrolyte loss, which can occur after PCD, and diminishes the risk of persistent collections and fistula [10, 12, 30, 43]. The current study was not able to show that EUSD had better outcomes compared to PCD in our study. Reported disadvantages of EUSD include inconvenient nasocystic drainage and repeated endoscopic interventions because of stent migration or incomplete drainage [44]. As a limitation of this technique, EUSD might not be feasible in all patients with PFC [45]. For example, the PFC needs to be in direct contact with the stomach for EUSD [14], so a pre-interventional computed tomography scan is advised to define the anatomic characteristics of the PFC.

EUSD outcomes are affected naturally by operator- and patient-dependent factors, such as the number and type of stents, physician's experience, and extent of the PFC [46, 47]. Regarding stent type, double pigtail stents may prevent stent migration thereby reducing the risk of re-intervention $[48,49]$. However, it may not be possible to insert two stents into some patients if the location or shape of the PFC is unsuitable [28], therefore appropriate patient selection is crucial [13]. In some cases, the PFC might contain solid debris from detached necrotic tissues. In these circumstances, EUSD might be useful not only for real-time detection of the debris through imaging but also for debriding the necrotic tissue and performing a direct necrosectomy, which is not possible via PCD [50, 51]. In patients with debris in the PFC, metal stents are thought to be superior to plastic stents due to their larger diameter $[52,53]$.

There are some limitations to the current study. The main weakness is the low number of two-arm studies and the small samples in the included studies. In addition, we were not able to carry out subgroup analyses for the type of pancreatic resections and for the type and number of stents. A further limitation is that the required data were not available in all studies, which reduced the power of the analysis. Besides, our analyses revealed shorter post-procedural hospital stay after EUSD compared to PCD; however, this can be significantly influenced by the primary surgical procedure and pre-procedural duration of stay, which might lead to bias in interpretation of outcomes of the analyses. Another weakness was the lack of randomized controlled trials that compared the outcomes of EUSD and PCD in patients with PFC.

In conclusion, the present study shows that EUSD is a safe and feasible approach to draining PFCs after pancreatic resections. EUSD provided a high technical and clinical success rate and a low rate of procedure-related complications and PFC recurrence. These encouraging features make EUSD an interesting option for treatment of PFC after pancreatic surgery. Satisfying outcomes can be achievable by meticulous patient selection and good technical experience. However, randomized trials with large patient cohorts are needed to comprehensively evaluate the advantages and disadvantages of this procedure compared with other drainage techniques.

Supplementary Information The online version contains supplementary material available at https://doi.org/10.1007/s00464-022-09137-6.

Funding Open Access funding enabled and organized by Projekt DEAL.

\section{Declarations}

Disclosures Ali Ramouz, Saeed Shafiei, Sadeq Ali-Hasan-Al-Saegh, Elias Khajeh, Ricardo Rio-Tinto, Sanam Fakour, Andreas Brandl, Gil Goncalves, Christoph Berchtold, Markus W. Büchler, and Arianeb Mehrabi have no conflicts of interest or financial ties to disclose.

Open Access This article is licensed under a Creative Commons Attribution 4.0 International License, which permits use, sharing, adaptation, distribution and reproduction in any medium or format, as long as you give appropriate credit to the original author(s) and the source, provide a link to the Creative Commons licence, and indicate if changes were made. The images or other third party material in this article are included in the article's Creative Commons licence, unless indicated otherwise in a credit line to the material. If material is not included in the article's Creative Commons licence and your intended use is not permitted by statutory regulation or exceeds the permitted use, you will need to obtain permission directly from the copyright holder. To view a copy of this licence, visit http://creativecommons.org/licenses/by/4.0/.

\section{References}

1. Caillol F, Godat S, Turrini O, Zemmour C, Bories E, Pesenti C et al (2019) Fluid collection after partial pancreatectomy: EUS drainage and long-term follow-up. Endosc Ultrasound 8(2):91-98. https://doi.org/10.4103/eus.eus_112_17

2. Vin Y, Sima CS, Getrajdman GI, Brown KT, Covey A, Brennan MF et al (2008) Management and outcomes of postpancreatectomy fistula, leak, and abscess: results of 908 patients resected at a single institution between 2000 and 2005. J Am Coll Surg 207(4):490-498. https://doi.org/10.1016/j.jamcollsurg.2008.05. 003

3. Loos M, Strobel O, Dietrich M, Mehrabi A, Ramouz A, AlSaeedi M et al (2021) Hyperamylasemia and acute pancreatitis after pancreatoduodenectomy: two different entities. Surgery 169(2):369-376 
4. Kawaida H, Kono H, Hosomura N, Amemiya H, Itakura J, Fujii H et al (2019) Surgical techniques and postoperative management to prevent postoperative pancreatic fistula after pancreatic surgery. World J Gastroenterol 25(28):3722-3737. https://doi.org/10.3748/ wjg.v25.i28.3722

5. Mehrabi A, Hafezi M, Arvin J, Esmaeilzadeh M, Garoussi C, Emami G et al (2015) A systematic review and meta-analysis of laparoscopic versus open distal pancreatectomy for benign and malignant lesions of the pancreas: it's time to randomize. Surgery 157(1):45-55. https://doi.org/10.1016/j.surg.2014.06.081

6. Strobel O, Cherrez A, Hinz U, Mayer P, Kaiser J, Fritz S et al (2015) Risk of pancreatic fistula after enucleation of pancreatic tumours. J Br Surg 102(10):1258-1266

7. Mehrabi A, Fischer L, Hafezi M, Dirlewanger A, Grenacher L, Diener MK et al (2014) A systematic review of localization, surgical treatment options, and outcome of insulinoma. Pancreas 43(5):675-686

8. Harnoss JC, Ulrich AB, Harnoss JM, Diener MK, Büchler MW, Welsch T (2014) Use and results of consensus definitions in pancreatic surgery: a systematic review. Surgery 155(1):47-57. https://doi.org/10.1016/j.surg.2013.05.035

9. Denzer UW, Sioulas AD, Abdulkarim M, Groth S, Rösch T, Busch P et al (2016) Endoscopic ultrasound-guided drainage of abdominal fluid collections after pancreatic surgery: efficacy and long-term follow-up. Z Gastroenterol 54(9):1047-1053. https://doi.org/10.1055/s-0042-112032

10. Tilara A, Gerdes H, Allen P, Jarnagin W, Kingham P, Fong Y et al (2014) Endoscopic ultrasound-guided transmural drainage of postoperative pancreatic collections. J Am Coll Surg 218(1):33-40. https://doi.org/10.1016/j.jamcollsurg.2013.09. 001

11. Cronin CG, Gervais DA, Castillo CF, Mueller PR, Arellano RS (2011) Interventional radiology in the management of abdominal collections after distal pancreatectomy: a retrospective review. AJR Am J Roentgenol 197(1):241-246. https://doi.org/10.2214/ ajr. 10.5447

12. Téllez-Ávila F, Carmona-Aguilera GJ, Valdovinos-Andraca F, Casasola-Sánchez LE, González-Aguirre A, Casanova-Sánchez I et al (2015) Postoperative abdominal collections drainage: percutaneous versus guided by endoscopic ultrasound. Dig Endosc 27(7):762-766. https://doi.org/10.1111/den.12475

13. Mohan BP, Shakhatreh M, Dugyala S, Geedigunta V, Gadalay A, Pahal P et al (2019) EUS versus percutaneous management of postoperative pancreatic fluid collection: a systematic review and meta-analysis. Endosc Ultrasound 8(5):298-309. https://doi.org/ 10.4103/eus.eus_18_19

14. Hookey LC, Debroux S, Delhaye M, Arvanitakis M, Le Moine O, Devière J (2006) Endoscopic drainage of pancreatic-fluid collections in 116 patients: a comparison of etiologies, drainage techniques, and outcomes. Gastrointest Endosc 63(4):635-643. https:// doi.org/10.1016/j.gie.2005.06.028

15. Cremer M, Deviere J, Engelholm L (1989) Endoscopic management of cysts and pseudocysts in chronic pancreatitis: longterm follow-up after 7 years of experience. Gastrointest Endosc 35(1):1-9. https://doi.org/10.1016/S0016-5107(89)72677-8

16. François E, Kahaleh M, Giovannini M, Matos C, Devière J (2002) EUS-guided pancreaticogastrostomy. Gastrointest Endosc 56(1):128-133. https://doi.org/10.1067/mge.2002.125547

17. Dumonceau JM, Delhaye M, Tringali A, Arvanitakis M, SanchezYague A, Vaysse T et al (2019) Endoscopic treatment of chronic pancreatitis: European Society of Gastrointestinal Endoscopy (ESGE) Guideline-Updated August 2018. Endoscopy 51(2):179-193. https://doi.org/10.1055/a-0822-0832

18. Page MJ, McKenzie JE, Bossuyt PM, Boutron I, Hoffmann TC, Mulrow CD et al (2021) The PRISMA 2020 statement: an updated guideline for reporting systematic reviews. BMJ 372:n71. https:// doi.org/10.1136/bmj.n71\%JBMJ

19. Sterne JA, Hernán MA, Reeves BC, Savović J, Berkman ND, Viswanathan M et al (2016) ROBINS-I: a tool for assessing risk of bias in non-randomised studies of interventions. BMJ 355:i4919. https://doi.org/10.1136/bmj.i4919

20. McGuinness LA, Higgins JPT (2020) Risk-of-bias VISualization (robvis): An R package and Shiny web app for visualizing riskof-bias assessments. Res Synth Methods. https://doi.org/10.1002/ jrsm. 1411

21. Guyatt G, Oxman AD, Akl EA, Kunz R, Vist G, Brozek J et al (2011) GRADE guidelines: 1. Introduction-GRADE evidence profiles and summary of findings tables. J Clin Epidemiol 64(4):383394. https://doi.org/10.1016/j.jclinepi.2010.04.026

22. Futagawa Y, Imazu H, Mori N, Kanazawa K, Chiba M, Furukawa $\mathrm{K}$ et al (2017) The effectiveness and feasibility of endoscopic ultrasound-guided transgastric drainage of postoperative fluid collections early after pancreatic surgery. Surg Laparosc Endosc Percutan Tech 27(4):267-272. https://doi.org/10.1097/sle.00000 00000000413

23. Donatelli G, Fuks D, Cereatti F, Pourcher G, Perniceni T, Dumont JL et al (2018) Endoscopic transmural management of abdominal fluid collection following gastrointestinal, bariatric, and hepatobilio-pancreatic surgery. Surg Endosc 32(5):2281-2287. https:// doi.org/10.1007/s00464-017-5922-1

24. Al Efishat M, Attiyeh MA, Eaton AA, Gönen M, Covey AM, D'Angelica MI et al (2019) Endoscopic versus percutaneous drainage of post-operative peripancreatic fluid collections following pancreatic resection. HPB (Oxford) 21(4):434-443. https:// doi.org/10.1016/j.hpb.2018.08.010

25. Tamura T, Kitano M, Kawai M, Tanioka K, Itonaga M, Kawaji $\mathrm{Y}$ et al (2019) Effectiveness of endoscopic ultrasound-guided drainage for noncapsulated postoperative pancreatic collection. Ther Adv Gastroenterol 12:1756284819884418. https://doi.org/ $10.1177 / 1756284819884418$

26. Storm AC, Levy MJ, Kaura K, Abu Dayyeh BK, Cleary SP, Kendrick ML et al (2020) Acute and early EUS-guided transmural drainage of symptomatic postoperative fluid collections. Gastrointest Endosc 91(5):1085-91.e1. https://doi.org/10.1016/j.gie.2019. 11.045

27. Gupta T, Lemmers A, Tan D, Ibrahim M, Le Moine O, Devière J (2012) EUS-guided transmural drainage of postoperative collections. Gastrointest Endosc 76(6):1259-1265. https://doi.org/10. 1016/j.gie.2012.07.037

28. Azeem N, Baron TH, Topazian MD, Zhong N, Fleming CJ, Kendrick ML (2012) Outcomes of endoscopic and percutaneous drainage of pancreatic fluid collections arising after pancreatic tail resection. J Am Coll Surg 215(2):177-185. https://doi.org/ 10.1016/j.jamcollsurg.2012.03.015

29. Varadarajulu S, Trevino JM, Christein JD (2009) EUS for the management of peripancreatic fluid collections after distal pancreatectomy. Gastrointest Endosc 70(6):1260-1265. https://doi. org/10.1016/j.gie.2009.06.007

30. Kwon YM, Gerdes H, Schattner MA, Brown KT, Covey AM, Getrajdman GI et al (2013) Management of peripancreatic fluid collections following partial pancreatectomy: a comparison of percutaneous versus EUS-guided drainage. Surg Endosc 27(7):24222427. https://doi.org/10.1007/s00464-012-2752-z

31. Mudireddy PR, Sethi A, Siddiqui AA, Adler DG, Nieto J, Khara $\mathrm{H}$ et al (2018) EUS-guided drainage of postsurgical fluid collections using lumen-apposing metal stents: a multicenter study. Gastrointest Endosc 87(5):1256-1262. https://doi.org/10.1016/j. gie.2017.08.011

32. Ilie M, Opriţă R, Şandru V, Berceanu D, Plotogea O, Constantinescu A et al (2018) EUS-guided transgastric drainage of 
intraabdominal fluid collections. Chirurgia (Bucur) 113(6):799808. https://doi.org/10.21614/chirurgia.113.6.799

33. Ergun M, Aouattah T, Gillain C, Gigot JF, Hubert C, Deprez PH (2011) Endoscopic ultrasound-guided transluminal drainage of pancreatic duct obstruction: long-term outcome. Endoscopy 43(6):518-525. https://doi.org/10.1055/s-0030-1256333

34. Kahaleh M, Hernandez AJ, Tokar J, Adams RB, Shami VM, Yeaton P (2007) EUS-guided pancreaticogastrostomy: analysis of its efficacy to drain inaccessible pancreatic ducts. Gastrointest Endosc 65(2):224-230. https://doi.org/10.1016/j.gie.2006.05.008

35. Kurihara T, Itoi T, Sofuni A, Itokawa F, Moriyasu F (2013) Endoscopic ultrasonography-guided pancreatic duct drainage after failed endoscopic retrograde cholangiopancreatography in patients with malignant and benign pancreatic duct obstructions. Dig Endosc 25(Suppl 2):109-116. https://doi.org/10.1111/den. 12100

36. Miranda A, Jürgensen C, Chekerov R, Chopra S, Gebauer B, Sehouli J (2021) EUS-guided transgastric drainage to manage a postoperative pancreatic fistula after distal pancreatectomy and splenectomy in recurrent ovarian cancer: a case report. Anticancer Res 41(7):3649-3656. https://doi.org/10.21873/anticanres.15155

37. Grobmyer SR, Hunt DL, Forsmark CE, Draganov PV, Behrns KE, Hochwald SN (2009) Pancreatic stent placement is associated with resolution of refractory grade $\mathrm{C}$ pancreatic fistula after left-sided pancreatectomy. Am Surg 75(8):654-657 (discussion 7-8)

38. Seewald S, Brand B, Groth S, Omar S, Mendoza G, Seitz U et al (2004) Endoscopic sealing of pancreatic fistula by using N-butyl2-cyanoacrylate. Gastrointest Endosc 59(4):463-470. https://doi. org/10.1016/s0016-5107(03)02708-1

39. Onodera M, Kawakami H, Kuwatani M, Kudo T, Haba S, Abe Y et al (2012) Endoscopic ultrasound-guided transmural drainage for pancreatic fistula or pancreatic duct dilation after pancreatic surgery. Surg Endosc 26(6):1710-1717. https://doi.org/10.1007/ s00464-011-2097-z

40. Singhal S, Rotman SR, Gaidhane M, Kahaleh M (2013) Pancreatic fluid collection drainage by endoscopic ultrasound: an update. Clin Endosc 46(5):506-514. https://doi.org/10.5946/ce.2013.46.5. 506

41. Bezmarević M, van Dijk SM, Voermans RP, van Santvoort HC, Besselink MG (2019) Management of (Peri)pancreatic collections in acute pancreatitis. Visc Med 35(2):91-96. https://doi.org/10. $1159 / 000499631$

42. Dorrell R, Pawa S, Pawa R (2021) Endoscopic management of pancreatic fluid collections. J Clin Med. https://doi.org/10.3390/ jcm10020284

43. Le Moine O, Matos C, Closset J, Devière J (2004) Endoscopic management of pancreatic fistula after pancreatic and other abdominal surgery. Best Pract Res Clin Gastroenterol 18(5):957975. https://doi.org/10.1016/j.bpg.2004.06.027

44. Prachayakul V, Aswakul P (2015) Endoscopic ultrasound-guided biliary drainage as an alternative to percutaneous drainage and surgical bypass. World J Gastrointest Endosc 7(1):37-44. https:// doi.org/10.4253/wjge.v7.i1.37

45. Arvanitakis M, Delhaye M, Bali MA, Matos C, Le Moine O, Devière J (2007) Endoscopic treatment of external pancreatic fistulas: when draining the main pancreatic duct is not enough.
Am J Gastroenterol 102(3):516-524. https://doi.org/10.1111/j. 1572-0241.2006.01014.x

46. Guo J, Duan B, Sun S, Wang S, Liu X, Ge N et al (2020) Multivariate analysis of the factors affecting the prognosis of walledoff pancreatic necrosis after endoscopic ultrasound-guided drainage. Surg Endosc 34(3):1177-1185. https://doi.org/10.1007/ s00464-019-06870-3

47. Varadarajulu S, Christein JD, Wilcox CM (2011) Frequency of complications during EUS-guided drainage of pancreatic fluid collections in 148 consecutive patients. J Gastroenterol Hepatol 26(10):1504-1508. https://doi.org/10.1111/j.1440-1746.2011. 06771.x

48. Giovannini M, Bories E, Téllez-Ávila FI (2012) Endoscopic ultrasound-guided bilio-pancreatic drainage. Endosc Ultrasound 1(3):119-129. https://doi.org/10.7178/eus.03.002

49. Itoi T, Itokawa F, Tsuchiya T, Kawai T, Moriyasu F (2009) EUSguided pancreatic pseudocyst drainage: simultaneous placement of stents and nasocystic catheter using double-guidewire technique. Dig Endosc 21(Suppl 1):S53-S56. https://doi.org/10. 1111/j.1443-1661.2009.00851.x

50. Shamah S, Okolo PI 3rd (2018) Systematic review of endoscopic cyst gastrostomy. Gastrointest Endosc Clin N Am 28(4):477-492. https://doi.org/10.1016/j.giec.2018.06.002

51. Rana SS, Sharma R, Kishore K, Dhalaria L, Gupta R (2021) Safety and efficacy of early ( $<4$ weeks of illness) endoscopic transmural drainage of post-acute pancreatic necrosis predominantly located in the body of the pancreas. J Gastrointest Surg. https://doi.org/10.1007/s11605-021-04945-y

52. Zhou X, Lin H, Su X, Zhang P, Fu C, Kong X et al (2021) Metal versus plastic stents for pancreatic fluid collection drainage: a systematic review and meta-analysis. J Clin Gastroenterol. https://doi. org/10.1097/mcg.0000000000001539

53. Saunders R, Ramesh J, Cicconi S, Evans J, Yip VS, Raraty M et al (2019) A systematic review and meta-analysis of metal versus plastic stents for drainage of pancreatic fluid collections: metal stents are advantageous. Surg Endosc 33(5):1412-1425. https:// doi.org/10.1007/s00464-018-6416-5

54. Wang L, Zhang Y, Chen B, Ding Y (2021) Endoscopic ultrasoundguided drainage in the management of postoperative pancreatic fistula after partial pancreatectomy. Turk J Gastroenterol 32(11): 979-987. https://doi.org/10.5152/tjg.2020.20841

55. Jürgensen C, Distler M, Arlt A, Brückner S, Ellrichmann M, Matthes K, et al (2019) EUS-guided drainage in the management of postoperative pancreatic leaks and fistulas (with video). Gastrointest Endosc 89(2):311-319. https://doi.org/10.1016/j.gie.2018. 08.046

56. Chen Y, Levy M, Moreels T, Hajijeva G, Will U, Artifon E, et al (2017) An international multicenter study comparing EUS-guided pancreatic duct drainage with enteroscopy-assisted endoscopic retrograde pancreatography after Whipple surgery. Gastrointest Endosc 85(21):170-177. https://doi.org/10.1016/j.gie.2016.07. 031

Publisher's Note Springer Nature remains neutral with regard to jurisdictional claims in published maps and institutional affiliations. 